\title{
Enhancing laos students' understanding of nature of science in physics learning about atom for peace
}

\author{
Phoxay Sengdala ${ }^{1 \& 2}$, Chokchai Yuenyong ${ }^{1 *}$ \\ ${ }^{1}$ Science Education Program, Faculty of Education, Khon Kaen University, Thailand \\ ${ }^{2}$ Faculty of Education, National University of Laos, Vientiane, Lao PDR. \\ For correspondence: ychok@kku.ac.th
}

\begin{abstract}
:
This paper aimed to study of Grade 12 students' understanding of nature of science in learning about atom for peace through science technology and society (STS) approach. Participants were 51 Grade 12 who study in Thongphong high school Vientiane Capital City Lao PDR, 1st semester of 2012 academic year. This research regarded interpretive paradigm. The intervention of STS physics provided 4 weeks of teaching about atom for peace through Yuenyong (2006) science technology and society (STS) approach. Students' understanding of nature of science was interpreted through students' worksheets, participant observation, students' journal writing and informal interview. The findings revealed that students could reflect their ideas related to three aspects of nature of science. This included Socio-cultural embeddedness, empirical basis, and subjectivity. The study has implications for NOS teaching in Lao PDR.
\end{abstract}

Keywords: nature of science, Lao PDR, physics, STS

\section{Introduction}

Lao People's Democratic Republic (Lao PDR) was established in 1975, after the fall of the Kingdom of Laos, following decades of war. The Constitution of Lao PDR, which was promulgated in 1991, recognizes the Lao People's Revolutionary Party as the leading nucleus of the political system. The Government of Lao PDR (GOL) is taking a development approach that guarantees the rights of all citizens, while at the same time promoting national unity. National development efforts in Lao PDR started only after the introduction of the New Economic Mechanism (NEM) in 1986 (Phetsiriseng, 2009).

The GOL is taking an approach of national development that guarantees the rights of all of its peoples at the same time that it promotes national unity. The GOL's long-term overarching goal is to exit the group of LDCs by 2020 through sustained equitable economic growth and social development, while safeguarding the country's social, cultural, economic, and political identity (GOL, 2006). The 8th Party Congress in March 2006 reemphasized its long-term national development goal of enabling Lao PDR to graduate from the ranks of LDCs by 2020 and to build the basic human and physical infrastructure for the shift to industrialization and modernity. In this connection, the Prime Minister and the Council of Ministers issued the guidance for the national education system reform consisting of six directions (MOE, 2008):

1. The national education system reform strategy aims to develop human resources that are applicable to the strategic development of the country's economic components as well as to the need to link the country with international goals.

2. Education reform should emphasize the national education structure. If change is to become a reality, then the attitudes and perceptions in society about the educational structural reforms need to be widely understood. 
3. The national education system reform strategy should be implemented with the participation of the society to ensure that education will continue to grow and develop.

4. The national education system reform strategy should expand the intellectual life, preserve the traditions and culture of the nation, and inspire a spirit of solidarity amongst the population throughout the country.

5. The national education system reform strategy should expand access to education, promote the capabilities of people, improve their living conditions, and compete and link with regional and international situations.

6. The national education system reform strategy should enhance the status of teachers and uphold the importance of their roles and positions.

In responding to the Dakar Framework of Action in 2000, the GOL endorsed in 2004 the National Education for All (EFA) Action Plan 2003-2015 (GOL 2004). The National Education for All Framework addressed that the Education Strategic Vision by 2010 and 2020, issued by the MOE in 2000, links education broader socio-economic development, as well as to the immediate local situation. It recognizes the need for lifelong educational opportunities to ensure that all persons can continue to upgrade their level of education as circumstances change during their lifetimes. The strategic vision seeks to mobilize education as a core component in overall human resources development for the development of Lao PDR. One of the most important commitments toward the achievement of the EFA goals was to reform the general education system to a 12-year system by adding one additional year in the lower secondary education, i.e. $(5+4+3)(\mathrm{GOL}, 2002$; MOE, 2008). According to policy of party about education in Laos was opened wide, such as there are extension a school throughout the country include the improving a lecturer. Education is the effect to develop economic of country evidently, but while education is hardly to changes. It is difficult to develop the economy of Laos to equality with the developed countries, especially the countries of ASEAN. Therefore, it is necessary to use the study to develop a national resource. Nowadays we will find that the study focuses on the students to learn on their own to give students an idea, how to learn and understand the content of learning, because learning stems from attention to acquiring knowledge which will have knowledge and understanding of critical thinking on their own, in around the world. However, science teaching in Lao PDR seemed to focus on content on the textbooks and teachers rather than inquiry scientific knowledge and learning science as way of knowing. This raised that Laos science education should concern on enhancing students' scientific literacy in order to obtain the vision of 2020. Yuenyong and Narjaikaew's (2009) work indicates that a common view of scientific literacy is that a scientist develops a 'scientific mind', or 'habits of mind'. Understanding scientists' habits of mind is a feature of the nature of science and an important aspect of scientific literacy and the public understanding of science.

Understanding the nature of science is an important aspect of scientific literacy, because engaging in the debate about socio-scientific issues requires some understanding of the nature of science. In everyday life, there are many kinds of socio-scientific issues e.g. debating human cloning and the genetic modification of foodstuffs, the role of nuclear power plants, environmental issues, global warming, preparing for natural disaster, and so on (Yuenyong, 2013). The nature of science (NOS) is a complicated concept. It is difficult for experts to define as it is for students to learn. NOS involves a wide variety of topics related to the history, philosophy, and sociology of science. Many have claimed that no consensus exists among philosophers of science, science educators as to a precise definition or characterization of the nature of science. However, there is consensus on many aspects of the nature of science that are relevant to K-12 students (Bell et al., 2000; Kourany, 1998; Good et al., 2000; Lederman, 1999; Lederman \& Abd-El-Khalick, 1998; Smith et al., 1997). These included the concepts that scientific knowledge is (a) tentative (subject to change); (b) empirically based (based on observations of the natural world); (c) subjective in that science is a human endeavor and investigations are conducted within the context of particular theoretical frameworks; (d) partly the 
product of inference, imagination, and creativity; (e) socially and culturally embedded (can be influenced by contextual factors outside of the scientific community); and (f) developed from a combination of observation and inferences.

To provide the citizen for Lao PDR vision of year 2020, Laos required scientific literacy person. Therefore, enhancing Laos students' understanding of nature of science should be run. In order to provide clearly practice of this study, Schwartz, Lederman and Crawford (2004) framework could be used as interpretation of NOS understanding. The NOS framework focused on following aspects; tentativeness of scientific knowledge, empirical basis, subjectivity, theories and laws, creativity, sociocultural embeddedness, and observations and inference. However, none of these aspects can be considered apart from the others. There is Interdependence of these aspects. Tentativeness: scientific knowledge is subject to change with new observations and with the reinterpretations of existing observations, Empirical basis: scientific knowledge is based on and/or derived from observations of the natural world, Subjectivity: science is influenced and driven by presently accepted scientific theories and laws. The development of questions, investigations, and interpretations of data are filtered through the lens of current theory, Creativity: scientific knowledge is created from human imaginations and logical reasoning, Socio-cultural embeddedness: science is a human endeavor and is influenced by the society and culture in which it is practiced, Observations and inference: science is based on both observation and inference. Observations are gathered through human senses or extensions of those senses. Inferences are interpretations of those observations, and Laws and theories: theories and laws are different kind of scientific knowledge. Laws describe relationships, observed or perceived of phenomena in nature. Theories are inferred explanations for nature phenomena and mechanisms for relationships among nature phenomena. And, Interdependence of these aspects, For example, tentativeness of scientific knowledge stems from the creation of that knowledge through empirical observation and inference. Each of these acts is influenced by the culture and society in which the science is practiced as well as by the theoretical framework and personal subjectivity of the scientist. As new data are considered and existing data reconsidered, inferences (again made within a particular context) may lead to changes in existing scientific knowledge (Schwartz et.al., 2004).

Understanding the nature of science knowledge referred to a human activity and the power and limitations of scientific knowledge. This encompasses the relationships between science, technology and society. There are some studies in Mekhong sub-region country, particular Thailand, which enhance students' understanding of NOS through science technology and society (STS) approach (Noinang, 2011; Attapan, 2012; Pato, 2012; Thipruetree, 2012, and Waisalong, 2012). These studies applied Yuenyong (2006) STS approach for enhancing students' understanding of NOS. Yuenyong (2006) used an STS approach to teach energy in a process that consisted of five stages: (1) identification of social issues; (2) identification of potential solutions; (3) need for knowledge; (4) decision-making; and (5) socialization stage. Therefore, this study could enhance Laos students' understanding of NOS in physics learning through Yuenyong (2006) STS approach. Each stage of his STS approach could be explained as following.

(1) Identification of social issues stage. This stage is designed to focus student attention and attitudes on learning about energy. The STS instruction has to begin in the realm of society. Instruction will be begun by posing issues related to scientific knowledge in society. These questions or problems of social issues need to be solved by citizens.

(2) Identification of potential solutions stage. Students plan to solve the social problem related to raising scientific knowledge. This stage supports students to concern with the technological aspects for find the possible solutions. Technological aspects are skills to support student decision making. Students need to think of what, why, and how ideas, design, systems, volition of application scientific knowledge work for that social problems. Teaching 
strategies may be used discussion among students' group, role-play, brain storming, searching information via internet, and discussion with expert (e.g. engineers or scientists).

(3) Need for knowledge stage. This stage involves developing scientific knowledge. Social questions and technological knowledge create the need to know some science content. Scientific concept was formulated in many strategies to help students to understand the technology and social issues. The strategies, for examples, include reflection reading document provided by teacher, and lecture. To give feedback students' understanding about scientific concept, the short quiz will be taken after class of this stage.

(4) Decision-making stage. This stage involves student in making a decision on how to use scientific knowledge and technology as solution of the social problem. This aspect public rhetoric about energy related technological and societal issues becomes dominated by dichotomies like 'chances and problem', 'advantages and disadvantages', or uses and abuses'. Student will be given chance to learn to choose between alternatives and in a thoughtful way systematically comparing as many relevant pro's and con's as possible. Teaching strategies may be used discussion among students' group, role-play, and brain storming.

(5) Socialization stage. Students need to act as people who are a part of society by reporting their proposal for solving problem. Socialization process will allow students to validate their values and scientific concepts for solutions during their sharing in society. Student might exhibit their solution in public by produce a poster, social medias, a newspaper article or a plan, present science project, or any activities that give students chance to sharing and learning from those social activities.

\section{Methodology}

This research is qualitative research regarded interpretive paradigm. The objective was to study of Grade 12 Students' Understanding of nature of science in learning about atom for peace through science technology and society (STS) Approach.

Participants

Participants included 51 Grade 12 who study in Thongphong high school, Vientiane Capital Laos PDR, 1st semester of 2012 academic year.

Intervention

The STS nuclear physics consist of two sub-units including nuclear for peace and safe life with radioactivity. The two sub-units consumed 16 hours of teaching. Intervention of the STS unit was taught by researcher who familiar to this school environment for 20 years. Researcher as teacher came to teach in the schools for two weeks before starting of intervention. These two weeks allow teacher and students getting to know each other, and also students' knowing how to learn science related to social issues and writing journal writing to reflect their learning. This study will only report the students' understanding of nature of science in learning about safe life with radioactivity. The activities of teaching and learning about safe life with radioactivity through Yuenyong (2006) STS approach were highlighted as Table 1. 
Table 1: Learning activities of Yuenyong (2006) STS atom for peace unit

\begin{tabular}{|c|c|c|c|}
\hline contents & lesson & learning activities & time \\
\hline $\begin{array}{l}\text { Atom for peace: } \\
\text { 1. The discovery } \\
\text { of radioactivity } \\
2 . \text { The transition } \\
\text { state nucleus. } \\
\text { 3. Isotope. } \\
\text { 4. The benefits } \\
\text { of radiation. }\end{array}$ & 1 & $\begin{array}{l}\text { 1. Identification of social issue stage } \\
\text { - Teacher give the students read the article and watch the video } \\
\text { about the atomic bombing, and let's them tell the reason, why it } \\
\text { happens. Teacher explains that, nowadays, there are many } \\
\text { countries have atomic bombs, but they have made a treaty to use } \\
\text { atomic energy in peaceful, and give a question "How does student } \\
\text { have the ways to use atomic energy in the peaceful". } \\
\text { - Teacher asked students about their feelings on the events and } \\
\text { consequences that occur. Teacher's comment that the "bomb" is } \\
\text { also called. "Nuclear bomb". } \\
\text { - The teacher still asked the students that students would like this } \\
\text { event to happen again in the future or not. Then, How should } \\
\text { students do? } \\
\text { - The teacher creates the topic for students to comment that "from } \\
\text { the power of the atomic bomb in the clip, will students have the } \\
\text { way to use atomic energy in the peaceful?". } \\
\text { - Students in each group brainstorm a variety of opinions on } \\
\text { issues that teachers give, by writing down each comment on } \\
\text { worksheets, and if you choose atomic energy to use in the peace, } \\
\text { just one way, What should you do. Then each group presented } \\
\text { their idea with the reasons for choosing it. }\end{array}$ & $2 \mathrm{Hrs}$ \\
\hline
\end{tabular}

Table 1: Learning activities of Yuenyong (2006) STS atom for peace unit (cont')

\begin{tabular}{|c|c|c|c|}
\hline cont & lesson & learning activities & time \\
\hline $\begin{array}{l}\text { Atom for } \\
\text { peace: } \\
\text { 1. The } \\
\text { discovery of } \\
\text { radioactivity } \\
2 . \quad \text { The } \\
\text { transition } \\
\text { state nucleus. } \\
\text { 3. Isotope. }\end{array}$ & 1 & $\begin{array}{l}\text { 2. Identification of potential solution sage: } \\
\text {-Each group to propose ways to use the nuclear energy in peaceful. } \\
\text { Then the teacher asked. "To answer these questions better, we have } \\
\text { to know about what, and how to find it?" to guide their learning. } \\
\text { 3. Need for knowledge stage: } \\
\text {-Teachers provide knowledge about the atomic, structure of the } \\
\text { atom. Then find the number of protons, neutrons and electrons of } \\
\text { the symbols of the nucleus, and learn the history of the discovery of } \\
\text { the atomic nucleus, ultimately the creation of the atomic bomb. }\end{array}$ & \\
\hline $\begin{array}{l}\text { 4. The benefits } \\
\text { of radiation. }\end{array}$ & 2 & $\begin{array}{l}\text { 3. Need for knowledge stage: } \\
\text { - Teachers review the sign of the nucleus }{ }^{A} X \text {. } \\
\text { - Teachers give the example: some elements with the same atomic } \\
\text { number. But different mass number, such as hydrogen, there are } \\
\text { three types: hydrogen }\left({ }_{1}^{1} \mathrm{H}\right) \text {, deuterium }\left({ }_{1}^{2} \mathrm{H}\right) \text { and tritium }\left({ }_{1}^{3} \mathrm{H}\right) \text {, and } \\
\text { indicated that the hydrogen there isn't neutron, there is one neutron } \\
\text { in deuterium and there are two neutrons in tritium. We call the } \\
\text { same element type but particles of neutrons is different that } \\
\text { "Isotope". } \\
\text { - Teacher explains on "isotopes", and then we separate isotopes of } \\
\text { element types in two: Stable isotopes are isotopes with stable } \\
\text { conditions, there is no release of energy and Radioactive isotope } \\
\text { that is releasing energy. Thus, a radioactive element to release } \\
\text { energy in the three types of radiation: alpha, beta and gamma } \\
\text { radiation, which is called. "Radioactive". }\end{array}$ & $2 \mathrm{Hrs}$ \\
\hline
\end{tabular}




\begin{tabular}{|l|l|l|l|}
\hline & $\begin{array}{l}\text {-teacher gives students to study the important properties of alpha, } \\
\text { beta and gamma radiation from the worksheet } 2 \text { on the topic: type } \\
\text { of radioactive and consider the table 1 on worksheet and also ask } \\
\text { the students, how scientists know that alpha, beta and gamma has } \\
\text { positive, negative or no electric charge. } \\
\text { - The teacher let students to write down their knowledge on } \\
\text { worksheet on the topic: usage of radioactive elements. }\end{array}$ & \\
\hline 3 & $\begin{array}{l}\text { 4. Decision making stage: } \\
\text { Ask the students, How scientific knowledge related with the } \\
\text { atomic bomb. How scientists associated related with World War II. } \\
\text {-Students watch a video clip about the "Nuclear War II" to show the } \\
\text { occurrence of World War 2 with the use of nuclear weapons that } \\
\text { destruction around the world. } \\
\text { - Teacher explains that there is a scene of violence, through the loss } \\
\text { of life and property, result is from a nuclear bombing that contain } \\
\text { in several thousand in the world. } \\
\text {-The teacher still asked: Students wishing to nuclear war happen in } \\
\text { the future or not, and do you think, how should to do. (Find the } \\
\text { way to protect, destruction or don't use nuclear weapon, use in the } \\
\text { right way or benefit). Concluded that we should use nuclear energy } \\
\text { for peace only. } \\
\text { 5. Socialization stage: } \\
\text { Students presented the results of their decisions, which involved in } \\
\text { the matter, local leaders or employees involved. Then write a } \\
\text { reflection of the published of their decision that, how students can } \\
\text { play a role in society. Learning the science make the students are } \\
\text { better or not. }\end{array}$ & \\
\hline
\end{tabular}

Data collection and analysis

Students' understanding of nature of science was interpreted through students' worksheets, participant observation, students' journal writing and informal interview. Students' ideas from these sources were coded, categorized and themed to represent their understanding of NOS regarding on Schwartz, Lederman and Crawford (2004) aspects of NOS. These aspects were labeled as following NOS1 tentativeness, NOS2 empirical basis, NOS3 subjectivity, NOS4 creativity, NOS5 socio-cultural embeddedness, NOS6 observations and inference, and NOS7 Laws and theories.

\section{Findings}

It found that the STS atom for peace unit could enhance students to express their ideas about nature of science. Some aspects of NOS were mentioned by students. However, small number of students held understanding of NOS in some aspect as showed in the Table 2. It indicated that the STS atom for peace unit could enhance students to understand NOS. However, the unit could not well enhance students to mention about all NOS aspects. There are only three aspects of NOS that was mentioned from all students. These included NOS5 Socio-cultural embeddedness, and NOS3 Subjectivity. And, they rarely mentioned about NOS2 Empirical basis. Students' understanding of NOS in each aspect will be explained as following.

Table 2: Students' understanding of NOS in the STS atom for peace unit

\begin{tabular}{|c|c|c|}
\hline \multicolumn{1}{|c|}{ Aspect of nature of science } & $\begin{array}{c}\text { Amount of students } \\
\text { understand NOS (N=51) }\end{array}$ & $\begin{array}{c}\text { Percentage of students } \\
\text { who understand NOS }\end{array}$ \\
\hline NOS2 Empirical basis & 4 & 7.84 \\
\hline
\end{tabular}




\begin{tabular}{|l|c|c|}
\hline NOS3 Subjectivity & 10 & 19.60 \\
\hline NOS5 Socio-cultural embeddedness & 37 & 72.54 \\
\hline
\end{tabular}

1. Understanding of the nature of science aspect 2: Empirical basis

Students, who understood aspect of empirical basis, have to find the answer from their own experience though critical thinking, rationality to find evidence of pursuit, experiment to confirm the answer. If students have discovered the answer or knowledge by themselves, they believed that scientific knowledge was derived from natural phenomenon, which requires evidence though critical thinking and rationality. Approximately eighteen percents of students could be interpreted as understanding of empirical basis. For example, S9 explained their group activity showing that he held rationality to find evidence of pursuit, experiment to confirm the answer as following.

"In learning process should be experiment or video clip to satisfy the more understanding the knowledge, because learning only theories are hard to understand and bored. So should be creating more experiment."

\section{Understanding of the nature of science aspect 3: Subjectivity}

Students, who understood aspect of subjectivity, have to understand that science is influences and being driven by the presently accepted scientific theories and laws. The development of questions, investigations, and interpretations of data are filtered through the lens of current theory. This is unavoidable subjectivity that allows science to progress and remain consistent, yet also contributes to change in science when previous evidence is examined from the perspective of new knowledge. Personal subjectivity is also unavoidable. Personal values, agendas, and prior experience dictate what and how scientists conduct their work. Approximately twenty percents of students could be interpreted as understanding of subjectivity. For example, S38 raised the agenda related to atomic as she mentioned below:

"Atomic production have to abreast with protecting, and the application correctly, and necessary. If not approved by the UN, then it should not be shooting or nuclear weapon test decisively."(S38)

\section{Understanding of the nature of science aspect 5: Socio-cultural embeddedness}

Students, who understood aspect of socio-cultural embeddedness, have to perceive that science is a human endeavor and is influenced by the society and culture in which it is practiced. The values of the culture determine what and how science is conducted, interpreted, accepted, and utilized. Approximately seventy percents of students could be interpreted as understanding of socio-cultural embeddedness.

"Application the radiation from the nuclear power provides many benefits, especially in the fields of science; it's very important and plays a role aspect of life, livelihood of man, and also to development the nation."

\section{Conclusion}

The STS atom for peace unit could enhance students to express their ideas about nature of science in some aspects including empirical basis, subjectivity and socio-cultural embeddedness. However, the findings suggested that one sub-unit could not enhance all aspects of NOS. The STS unit should be continuously provided for Lao students to fill up all aspects of NOS. For further study, the explicit NOS teaching should be developed for context of Laos science education. The ministry of education and other Laos science educational institute should more enhance students' understanding of NOS in science teaching. 


\section{Rerferences}

Attapan, N. (2012). The Study of Grade 11 Students' Understanding of nature of science (NOS) in Learning about Lights through Science Technology and Society (STS) Approach for Explicit NOS. Unpublished Master of Education in Science Education thesis, Khon Kaen University.

Bell, R. L., Lederman, N. G., \& Abd-El-Khalick, F. (2000). Developing and acting upon one's conception of the nature of science: A follow-up study. Journal of Research in Science Teaching, 37, 563-581.

Good, R., Lederman, N., Gess-Newsome, J., McComas,W.,\&Cummins, C. (2000). Nature of science: Implications for research, assessment, and teacher education. A symposium and paper presented at the annual international meeting of the Association for the Education of Teachers in Science, Akron, OH.

Government of Lao PDR (GOL) (2002). Ministry of Education, No. 1500/DOP.02. Decree on Implementing the Decentralization in Education Sector. Vientiane: Ministry of Education.

Government of Lao PDR (GOL) (2004). National Education for All Action Plan, 2003-2015. Vientiane: Ministry of Education.

Government of Lao PDR (GOL) (2006). National Socio-Economic Development Plan (NSEDP), 2006-2010. Vientiane: Ministry of Education.

Lederman, N. G. (1999). Teachers' understanding of the nature of science: Factors that facilitate or impede the relationship. Journal of Research in Science Teaching, 36, 916-929.

Lederman, N., \& Abd-El-Khalick, F. (1998). Avoiding de-natured science: Activities thatpromote understandings of the nature of science. In W. F. McComas (Ed.), The nature of science in science education: Rationales and strategies (pp. 82-126). Boston: Kluwer Academic Publishers

MOE (2008). Education for All: Mid-Decade Assessment. Vientiane: MOE.

Noinang, S. 2011. Grade 11 Students' Understanding about Nature of Science in Learning about Earth and Changing through STS Approach and Explicit Nature of Science. Unpublished Master of Education in Science Education thesis, Khon Kaen University.

Pato, K. (2012). Grade 10 Students Understranding of Nature of Science in Learning about Energy through Science Technology and Society (STS Approach) for Explicating NOS. Unpublished Master of Education in Science Education thesis, Khon Kaen University.

Phetsiriseng, I. (2009). Education Reform Context and Process in Lao PDR: Focusing on Basic Education. In Y. Hirosato, and Kitamura, Y. (Eds.), The Political Economy of Educational Reforms and Capacity Development in Southeast Asia (pp. 265 - 282), The Netherland: Springer

Schwartz, R.S., Lederman, N.G., and Crawford, B.A. (2004). Developing Views of Nature of Science in an Authentic Context: An Explicit Approach to Bridging the Gap Between Nature of Science and Scientific Inquiry. Science Education, 88: 610 - 645

Smith, M. U., Lederman, N. G., Bell, R. L., McComas, W. F., \& Clough, M. P. 1997. How great is the disagreement about nature of science? A response to Alters. Journal of Research in Science Teaching, 34, 1101-1104.

Thipruetree, S. (2012). Problem Solving Ability and Science Learning Achievement about Genetic and Biotechnology of Mathayomsuksa IV Students Taught Through Science Technology and Society (STS Approach). Unpublished Master of Education in Science Education thesis, Khon Kaen University.

Waisalong, P. (2012). Students' Understanding of The Nature of Science by Using Science Technology and Society (STS) Approach in Biodiversity. Unpublished Master of Education in Science Education thesis, Khon Kaen University.

Yuenyong, C. 2006. Teaching and Learning about Energy: using STS approach. Unpublished PhD thesis, Kasetsart University. Yuenyong, C. (2013). Enhancing Scientific Literacy in Thailand. Global Studies of Childhood, 3(1): 86 - 98

Yuenyong ,C. \& Narjaikaew, P. (2009). Science Literacy and Thailand Science Education. International Journal of Environmental and Science Education, (July), 335-349.

Yuenyong, C \& Sumranwanich, W. (2009). Teaching of Science, Technology and Society. Khon Kaen : Department of Science Education. Faculty of Education Khon Kaen University. 